DEMOGRAPHIC RESEARCH

VOLUME 28, ARTICLE 26, PAGES 733-762

PUBLISHED 5 APRIL 2013

http://www.demographic-research.org/Volumes/Vol28/26/

DOI: 10.4054/DemRes.2013.28.26

Research Article

\title{
Working life gain from gain in old age life expectancy in India
}

\section{Preeti Dhillon \\ Laishram Ladusingh}

\section{(C) 2013 Dhillon \& Ladusingh.}

This open-access work is published under the terms of the Creative Commons Attribution NonCommercial License 2.0 Germany, which permits use, reproduction \& distribution in any medium for non-commercial purposes, provided the original author(s) and source are given credit.

See http:// creativecommons.org/licenses/by-nc/2.0/de/ 


\section{Table of Contents}

1 Introduction $\quad 734$

$2 \quad$ Need for the study $\quad 735$

$3 \quad$ Data and methods $\quad 737$

$\begin{array}{lll}3.1 & \text { Data sources } & 737\end{array}$

3.2 Method 738

3.2.1 Projection of age-specific work participation rates 738

$\begin{array}{lll}\text { 3.2.2 Projection of life expectancy } & 740\end{array}$

$\begin{array}{ll}\text { 3.2.3 Old age dependency ratio } & 740\end{array}$

$4 \quad$ Findings and discussion 741

4.1 Projected age specific work participation rates by sex and residence 741

$\begin{array}{lll}4.2 & \text { Projected life expectancy at age } 60 \text { years by sex } & 746\end{array}$

$\begin{array}{lll}4.3 & \text { Projected working life expectancy at age } 60 \text { years } & 747\end{array}$

4.4 Old age dependency ratio adjusted for work participation 750

4.5 Projected old age dependency adjusted for work participation by 752

4.6 Validating projections with the recent survey of NSS (2009-10) 754

$5 \quad$ Summary and conclusion $\quad 755$

$6 \quad$ Acknowledgement 756

$\begin{array}{ll}\text { References } & 757\end{array}$

$\begin{array}{ll}\text { Appendix } & 761\end{array}$ 


\title{
Working life gain from gain in old age life expectancy in India
}

\author{
Preeti Dhillon $^{1}$ \\ Laishram Ladusingh ${ }^{2}$
}

\begin{abstract}
BACKGROUND

It is important to evaluate the interaction between increasing life expectancy and changing age patterns in work participation from the perspective of planning for the greying population of India.
\end{abstract}

\section{OBJECTIVE}

This study attempts to answer the question, "Does longevity translate into longer work participation, and further, what are the prospects of old age dependency?”

\section{METHODS}

We project work participation rates (WPR) using two rounds of National Sample Survey data and adopting a cohort approach up to the year 2050, then integrate these projected WPRs with projected life tables to obtain working life tables, so as to assess the average years of working life.

\section{RESULTS}

We find a decline in WPR from 56.2 to 54.3 per cent among elderly males and an increase from 22.2 to 29.6 per cent among elderly females, during the period 2010-50. Projected working life expectancy (WLE) shows significant gain for both males and females; however, remaining working life as a percentage of remaining life will decrease for males but will increase for females. The old age dependency ratio (ODR) is significantly higher for females than for males. Adjusted ODR (AODR) will increase from 11.4 to 26.3 per cent in the same period. However, there is a 10 per cent shift from female to male contribution in ODR by 2030.

\section{CONCLUSIONS}

Longevity is not translating into longer economic activity for males. For females, longer life expectancy does prolong economic activity. In urban areas, longevity improvements support a longer working life, but the same is not true for rural areas. Moreover, adjusted ODR is higher for females in urbanized states of India.

1 International Institute for Population Sciences, India. E-Mail: pdhillon_maths@yahoo.co.in. 2 International Institute for Population Sciences, India. E-Mail: Islaishram@iips.net. 


\section{Introduction}

The annual rate of growth of the population aged 60 and above in India is higher than the rate of growth of the total population. At the prevailing pace of demographic transition, population ageing is inevitable. The proportion of the population aged 60 and above is projected to touch 19.1 per cent in 2051, from the current figure of 8.1 per cent. In terms of absolute number, the increase is from 86.5 to 298.2 million during 2011-2051 (Rajan 2010). The main policy concern in anticipation of the steady increase in the absolute number of population aged 60 years and above is providing social assistance and long-term care, which is going to be far beyond the carrying capacity of the working-age population. In India, important social security, poverty alleviation and social welfare measures are being implemented by various ministries, along with central and individual state departments and civil societies. These include the Public Distribution System (PDS), the Mahatma Gandhi National Rural Employment Guarantee Scheme (MGNREGS), the Indira Awaas Yojana (IAY) and the Indira Gandhi National Old Age Pension Scheme (IGNOAPS) among others. However, India allocates only about 2 per cent of GDP to social protection programmes (Krzysztof et. al. 2009). Despite the efforts of the government, public expenditure in social protection programmes is very low, and only about 11 per cent of the labour force is covered by some social security programme.

Working longer and extending support to those who work longer can ease the social and economic burden of ageing of the population to a considerable extent. In India, retirement age in the public and private sectors varies from 55 to 65 years (Rajan 2010). Retirement age from government and established corporate firms is governed by regulations, while for workers in the unorganized sector, retirement can be either voluntary or involuntary. Early retirement from a formal job is attractive because of incentives and other retirement packages, while early voluntary retirement from the job in the unorganized sector is an expression of satisfaction and achievement in life. The rapid post-war growth of institutionalized social security and other pension benefits are the major source of retirement income in developed countries (Crawford and Lilien 1981). Studies (Boskin 1977; Quinn 1977 and Lilien 1982) have found that generous social security in the developed countries lowers the probability of work participation in old age. However, the situation in India is different: around 94 per cent of the total labour force, encompassing 370 million workers, is part of the informal economy; old people are typically poor (Mohanty and Sinha 2010), and benefits from public schemes in kind and cash transfer are not adequate to meet the consumption needs of the elderly (Narayana 2011). As a result, elderly people continue to work even when they are past retirement age, mostly in the unorganized sector and in lower-paying work (Ladusingh and Narayana 2011a). A study based on Census of India data (Bhagat and Unisa 2006) 
has found that 40 per cent of the population aged 60 years and above is still working, and 61 per cent of them are males.

Following Krishnan (1977), Dhillon and Ladusingh (2011) based on the analysis of working life table disaggregated by sex, found that the average years of working life at age 60 and above for males and females was 9.3 and 3.8 years in 2001. The present paper is an extension of this finding, projected into the future. In this paper we shall project WPRs of the population 55 years and above by sex from 2010 to 2050 . We shall also project age-specific death rates (ASDR) by sex and construct working life tables for the same period. The analysis and presentation of results on old age dependency is restricted to major states in India. The purpose of this paper is to add to the understanding of how many of the added years of life, particularly at 60 and above, translate into longer work participation by elderly. For India, this information is crucial policy input for the reorientation of social assistance programmes. The scientific contribution lies in the meaningful application of demographic techniques to meet the need of public policy. Evidence-based policies are more realistic and less subject to risks.

The paper is organized as follows. In the next section, a brief account of the need for this study is presented, followed by a section on data sources, methodology and assumptions. The third section discusses the findings and the last section presents the summary and conclusion.

\section{Need for the study}

Labour force participation rates in recent studies are evident from ILO (2009), Kim (2010), Schrier (2010), Harrower (2007) and Burniaux et al. (2003). Nurminen et al. (2005) have constructed WLE for Finnish municipal workers to assess, on an average, how long 45 year old workers continue to work. In the Indian context, Krishnan (1977) has made a snapshot attempt to assess average remaining years of working life after age 60 years. Dhillon and Ladusingh (2011) studied the changing pattern of working life for males and females between 1971 and 2001. Audinarayana (2001) and Kumar and Anand (2006) have provided some evidence of the higher elderly work participation in India. Most of the other studies (Gulati and Rajan 1991; Rajan et al. 1999; Gore 1992; Dandekar 1996) in India are based on situational analysis and have limited relevance for the future perspective. This study is prospective in nature and is an attempt to bridge the gap in research needed for policy and programmes.

Work participation at older ages not only promotes active ageing from an individual's perspective but can also lighten the fiscal burden of population ageing. However, translation of gain in life expectancy, particularly at age 60 and above, into 
work participation is a complex phenomenon governed by the interplay of a host of supporting factors. These include the share of organized and unorganized sectors in the economy of the country, productivity and wage at advanced age, and market response to population ageing. In India only about 11 per cent of the total workforce is engaged in formal jobs in the organized sector while the rest is in informal jobs including casual labour, daily wage earners and self employed. Men and women employed in the formal sector in rural areas account for 9.1 and 3.7 per cent of the respective totals (National Sample Survey Organization 2006). On the other hand, in urban areas the corresponding figures for men and women are 40.6 and 35.6 per cent, respectively. This represents a case of urban bias in employment, particularly in the formal sector, since 68 per cent of India's population lives in rural areas. Further, the public sector share of workers in formal jobs is 62 percent (Rajan 2010). Institutional and social barriers have resulted in labour market segmentation, which has come in the way of dissemination of the benefits of economic growth to workers across regions and social groups (Kundu and Mohanan 2008). As a consequence, though India is in an advantageous position in terms of labour market due to fast changing age distribution, it does not ensure that employment opportunities will be equal in all sectors. For this reason, in recent times the emphasis has been on improving the quality of the labour force, in terms of educational attainment and technical skills (Planning Commission 2008). Central, state, government undertaking firms and corporate firms constitute the organized sector, in which retirees are either fully or partially covered by the retirement schemes. Casual labourers, daily wage earners, workers in unregistered, small-scale industries, selfemployed workers, etc. are components of the unorganized sector. Government expenditure for retirees from the unorganized sector is minimal and restricted to social assistance, which is not adequate to meet subsistence needs.

Association between age and productivity counts when it comes to work participation at old age. A combination of physical conditions, cognitive performance, mental abilities, education and experience determine the productivity of an individual. Skirbekk et al. (2012) have shown that mental abilities and education outweigh other factors in determining productivity. In the case of India, among adults at least 45 years of age, men and women could recall 5.2 and 4.6 words on an average out of 10 on a cognitive performance test, 5.8 and 7 per cent of men and women respectively had some problem in performing the activities of daily living (ADL) and 57.4 and 40.7 per cent respectively were literate (Arokiasamy et al. 2011). Against this backdrop, the productivity of the Indian elderly appears negligible; however, rising cohorts of the elderly are expected to have more of the skills associated with productivity. Investment in human resource development can enhance the knowledge and skills of later cohorts of the elderly, to make opportunities in emerging industries and a service-based economy available to them. Investment in health with a focus on geriatric care will need 
to be increased gradually from the present level of around 1.1 per cent of GDP to at least 6 per cent, to curtail the negative impact of chronic illness and disabilities on labour market participation, as evident from the study by Uppal and Sarma (2007). Besides the important aspects of work participation by the elderly are the unpredictable changes in the supply and demand side of the labour market. For a gradually ageing population, such as in India, the challenge of generating a sufficient number of jobs to absorb a rapidly growing workforce has been successfully met, as is evident from the finding that the first demographic dividend will last till 2035 (Ladusingh and Narayana 2011b). It is also to be reiterated that population ageing may not necessarily reduce economic growth, if countervailing factors prevail (Vodopivec and Arunatilake 2008).

This section has detailed the multiple factors and conditions pertaining to demographic change, institutional and social barriers, mental or chronic illness and morbidity, market conditions and fiscal policies, which will have a bearing on work participation by the elderly. An abstraction of the complex interplay of these factors in simple terms of WLE at 60 and above shall be the basis for answering the key question of whether gain in life expectancy translates into longer work participation. This study will provide a virtual depiction of the long-term scenario for India.

\section{Data and methods}

\subsection{Data sources}

The National Sample Survey Organization (NSSO) has been producing comprehensive surveys of employment and unemployment in India through its quinquennial surveys since 1973. This paper uses data from the $55^{\text {th }}(1999-2000)$ and $61^{\text {st }}(2004-05)$ rounds of NSSO for preparation of base data for projection of age-specific WPRs. The survey design adopted was multi-stage stratified sampling. Census villages and urban frame survey (UFS) blocks of NSSO are the sampling frames for selection of representative rural and urban first stage units (FSU). All rural and urban areas within districts formed rural and urban strata for selection of FSU. Probability proportional to size sampling with replacement was followed for rural sampling and equal probability sampling without replacement for urban sampling. Households from each rural and urban stratum are second stage units (SSU) of sampling, and are divided into three sub-strata: affluent households in one, households in agricultural occupations in the second, and all remaining households in the third. Data collection is spread over three rounds of four months duration to control for seasonal variation. In addition to household socioeconomic status, ownership of housing, land and other assets, individual members' 
particulars of age, sex, educational attainment, and employment status were also collected.

NSSO defines principal usual activity status as 'the activity status on which a person spent relatively longer time during the 365 days preceding the date of the survey' and subsidiary activity status as 'the activity status on which a person has pursued some economic activity for a relatively shorter time during the same 365 days preceding the date of the survey'. In the present study, WPRs are calculated combining both the principal usual activity and subsidiary usual activity; these are comparable to census work (main and marginal) participation rates. It should be noted that, unlike labour force participation rates, WPR does not include non-workers who are 'seeking for work' or 'available for work'.

We project age-specific WPRs for five-year age groups using the entry and exit cohort method for every five-year interval from 2010 to 2050. These rates are input for construction of the working life table from 2010 to 2050.

The Sample Registration System (SRS) of the Registrar General of India (RGI) is the main source of age-specific death rates (ASDR) at the state level. This paper uses the annual ASDR from SRS for the period 1970-2006 to project age-specific mortality rates. SRS collects details of deaths in representative sampled rural and urban units for states and Union Territories continuously by local enumerators and then matches these with supervisors' details, collected on a half-yearly basis for finalization of death events. For the assessment of dependency ratio adjusted for age-specific WPRs up to 2050 the UN World Population Prospects, 2008 revision is the input data source. The projected population for the states up to 2026 is taken from the Report by the ORGI (2006).

\subsection{Method}

\subsubsection{Projection of age-specific work participation rates}

Age-specific WPRs for five-year age groups are projected using the entry and exit cohort method for every five-year interval from 15-19 to 80-84 and 85+ for the period 2010 to 2050. The method was initially developed by the Organization for Economic Co-operation and Development (Burniaux et al. 2003) and later expanded upon by the Australian Government Productivity Commission Research Report (2005). These studies were the basis for a model developed by BC Stats (Harrower 2007) which provides the foundation for the projection, and also by Dan Schrier (2010). The method is briefly outlined as follows. 
The inputs for the method are the rates of entry into, or exit from, the labour force, for each five-year age group for ages 15 and above up to age 84, and separately for age 85 and above. These entry and exit rates are then applied to existing cohort participation rates to project their future participation. Equation (1) displays the formula used to calculate entry rate at time $t$ for the cohort aged between $\mathrm{x}$ and $\mathrm{x}+4$ :

$$
\mathrm{EN}_{\mathrm{x}, \mathrm{x}+4}^{\mathrm{t}}=\left(\mathrm{PR}_{\mathrm{x}+5, \mathrm{x}+9}^{\mathrm{t}}-\mathrm{PR}_{\mathrm{x}, \mathrm{x}+4}^{\mathrm{t}-5}\right) /\left(0.99-\mathrm{PR}_{\mathrm{x}, \mathrm{x}+4}^{\mathrm{t}-5}\right)
$$

where PR denotes participation rate with a maximum value of 0.99 .

Entry rates are the difference in participation rates of a five-year age cohort at time $\mathrm{t}$ and $\mathrm{t}-5$ divided by the portion of that cohort that is available to participate in the labour force, but is not yet in the labour force at time t-5.

Exit rate at time $t$ for the cohort aged between $x$ and $x+4$ is obtained from

$$
\mathrm{EX}_{\mathrm{x}, \mathrm{x}+4}^{\mathrm{t}}=\left(\mathrm{PR}_{\mathrm{x}, \mathrm{x}+4}^{\mathrm{t}-5}-\mathrm{PR}_{\mathrm{x}+5, \mathrm{x}+9}^{\mathrm{t}}\right) / \mathrm{PR}_{\mathrm{x}, \mathrm{x}+4}^{\mathrm{t}+5}
$$

We calculate the entry and exit rates separately for males and females. Entry and exit rates include both positive and negative values; where an age group has a positive entry rate, an entry rate is used for projection in that age group; otherwise, an exit rate is used. Entry and exit rates are calculated throughout the projection using projected participation rates so that existing cohort effects will continue to be reflected throughout the projection period. For the period 2000-05, these rates are presented in Figure (a) (see Appendix). It should be noted that, for the projection period, these entry and exit rates are not constant at 2000-05; these are calculated for every period based on the projected WPR for the preceding period.

For positive entry rates, projected age-specific WPRs are obtained from

$$
\mathrm{PR}_{\mathrm{x}+5, \mathrm{x}+9}^{\mathrm{t}}=\mathrm{EN}_{\mathrm{x}, \mathrm{x}+4}^{\mathrm{t}-5} *\left(0.99-\mathrm{PR}_{\mathrm{x}, \mathrm{x}+4}^{\mathrm{t}-5}\right)+\mathrm{PR}_{\mathrm{x}, \mathrm{x}+4}^{\mathrm{t}-5}
$$

Similarly, for positive exit rates, projection of age-specific WPRs are calculated using the following equation:

$$
\mathrm{PR}_{\mathrm{x}+5, \mathrm{x}+9}^{\mathrm{t}}=\left(1-\mathrm{EX}_{\mathrm{x}, \mathrm{x}+4}^{\mathrm{t}-5}\right) * \mathrm{PR}_{\mathrm{x}, \mathrm{x}+4}^{\mathrm{t}-5}
$$




\subsubsection{Projection of life expectancy}

The Lee and Carter (1992) model has been used extensively for various types of projection in demography. Population projections (Booth and Tickle 2003), the forecasting of sex differentials in mortality (Carter and Lee 1992), and the projection of mortality patterns for the "oldest-old"' (Buettner 2002) are few examples of it. The Lee and Carter model assumes that the trajectory of death rates over time depends on a single time varying parameter. It models the force of mortality $\mathrm{m}_{\mathrm{xt}}$ at age $\mathrm{x}$ and time $\mathrm{t}$ as a log-bilinear function,

$$
\log m_{x t}=a_{x}+b_{x} k_{t}+e_{x t}
$$

where $\mathrm{a}_{\mathrm{x}}$ represents average level of $\log m_{x t}$ surface over time, $\mathrm{k}_{\mathrm{t}}$ is the time-varying index of the level of mortality and $\mathrm{b}_{\mathrm{x}}$ capture the sensitivity of $\log m_{x t}$ at age $\mathrm{x}$ to variation in $\mathrm{k}_{\mathrm{t}}$.

The error term $\mathrm{e}_{\mathrm{xt}}$ reflects age-period effects, which are not captured by the model.

We have used the Lee-Carter model to forecast ASDR up to year 2050. Finally, we project ASDR to generate life expectancy for the coming years. Using projected figures of WPRs for each five-year interval and numbers of survivors, working life tables are constructed. We used the multiple decrement method given by Sullivan (1971) in the construction of working life tables from 2010 to 2050 by male, female and place of residence.

\subsubsection{Old age dependency ratio}

Gain in life expectancy has raised questions regarding the validity of conventional measures of population ageing and dependency ratios, based either on chronological age or age distribution, in the context of comparability across countries. The conventional measures, no doubt, are easy to comprehend, and age distribution data are readily available but reflect neither remaining years of life nor engagement in economic activities. To capture gain in life expectancy, Sanderson and Scherbov (2005) proposed the median age of population, standardized for expected remaining years of life, as a new measure of population ageing. Further, they proposed a measure of dependency ratio rescaled for increase in life expectancy at birth, and they found this index more stable than the conventional age dependency ratio (ODR). Sanderson and Scherbov (2010) argued that, as life expectancy increases, people remain healthy longer, and they proposed two alternative measures of dependency, namely, prospective old age dependency ratio (POADR) and adult disability dependency ratio (ADDR). They 
defined POADR as the ratio of the number of persons in age groups with life expectancies above 15 years to the number of persons at least 20 years old with life expectancies greater than 15 years, and ADDR as the ratio of adults with disabilities aged at least 20 years to the number of adults without disabilities in the same age bracket. In the present study, we propose adjusted old age dependency ratio (AODR) as a new measure of ODR and compare it with the conventional one. The rationale of AODR is that not everyone of post retirement age is dependent; some continue to work. Mathematically, the present study defines old age dependency as given below:

1) Conventional old age dependency ratio:

$$
\text { ODR }=\frac{\operatorname{Pop}(60+)}{\operatorname{Pop}(15-59)}
$$

2) Adjusted old age dependency ratio:

$$
\operatorname{AODR}=\frac{\left(1-\mathrm{WPR}_{60+}\right) * \operatorname{Pop}(60+)}{\mathrm{WPR}_{15-59} * \operatorname{Pop}(15-59)}
$$

where WPR stands for work participation rate of the respective age group.

\section{Findings and discussion}

\subsection{Projected age specific work participation rates by sex and residence}

The projected WPR for the years 2010, 2030, and 2050, based on past cohorts' experience for the years 1999-2000 and 2004-05, are shown in Figure 1. For the convenience of comparison over time, the age-specific WPR for each year of projection is normalized; that is, divided by the average WPR of the prime working age group of 30-49 years. Normalized work participation value of 1 implies that the WPR of a particular age group is at par with the average WPR of prime workers. The distinguishing feature of the age pattern of work participation among males is that, compared to the prime working age group of 30-49 years, elderly WPRs are much lower from 55 years age onwards as it drops below the horizontal parity line as the measure by the normalized scale value of 1 . More specifically for the age groups 55-59, 60-64, 65-69, 70-74, 75-79, 80-84 and 85+ WPRs are lower by 10, 20, 40, 50, 70, 80 and 90 per cent, respectively, than that of the prime working age group. In addition, over time male age-specific WPRs remain unchanged from 2010 to 2050 and there is no sign of working longer after the average retirement age. The same pattern is true for 
males in rural areas, with the exception that age span of work participation is longer by about 5 years and work participation starts declining from 59 years onwards. For rural male age groups 60-64, 65-69, 70-74, 75-79, 80-84 and 85+ WPRs are lower by 20, 30, 50, 60, 70 and 90 per cent, respectively, than that of prime working age group 30-49 years. In urban areas the span of work participation among males is much shorter, and declines faster after 55 years, than in rural areas. A noteworthy observation is that urban male WPR has shown marginal increase over time.

When it comes to age pattern of WPR among females, it is interesting to note that older-adult women WPRs are higher than that of the prime age group regardless of residence background, and also that female WPR starts declining 5 years later than that of males. From 2010 to 2050 female WPRs at older ages show a rapid increase. This is in contrast to the pattern for male WPRs. The result is along expected lines, as more and more opportunities, particularly in hospitality industries and secretarial services, are expected to open up in the future. There is no doubt that women are likely to avail themselves of such opportunities as more girls are enrolling for primary and higher levels of education than in the past. The results of the expected work participation of women in future also partly suggests translation of longer life into longer economic activity, as with declining fertility, more women would be available for work.

Table 1 shows the projected work participation rates by sex for broad age groups from 55 years onwards from 2010 to 2050. The enhancement in overall WPR of the population 60 years and above is largely because of the increase in female WPR of corresponding age group by 7.4 per cent points, from 22.2 per cent in 2010 to 29.6 per cent in 2050. While, WPR of males at age 60 and above shows a gradual decline, the WPR among elderly males is higher than that of their female counterparts.

For each period of projection and for both the sexes, WPRs decline sharply with advancing age. Over the period, WPRs continue to increase marginally by 1 to 2 percentage points among older adults and elderly males in the age groups 55-59 to 6569 years, but not after age 70 years. However, among elderly females, WPRs continue to increase for all age groups, but the levels are much lower than that of males. 
Figure 1: Normalized age-specific work participation rates for India by sex and residence, 2010-50
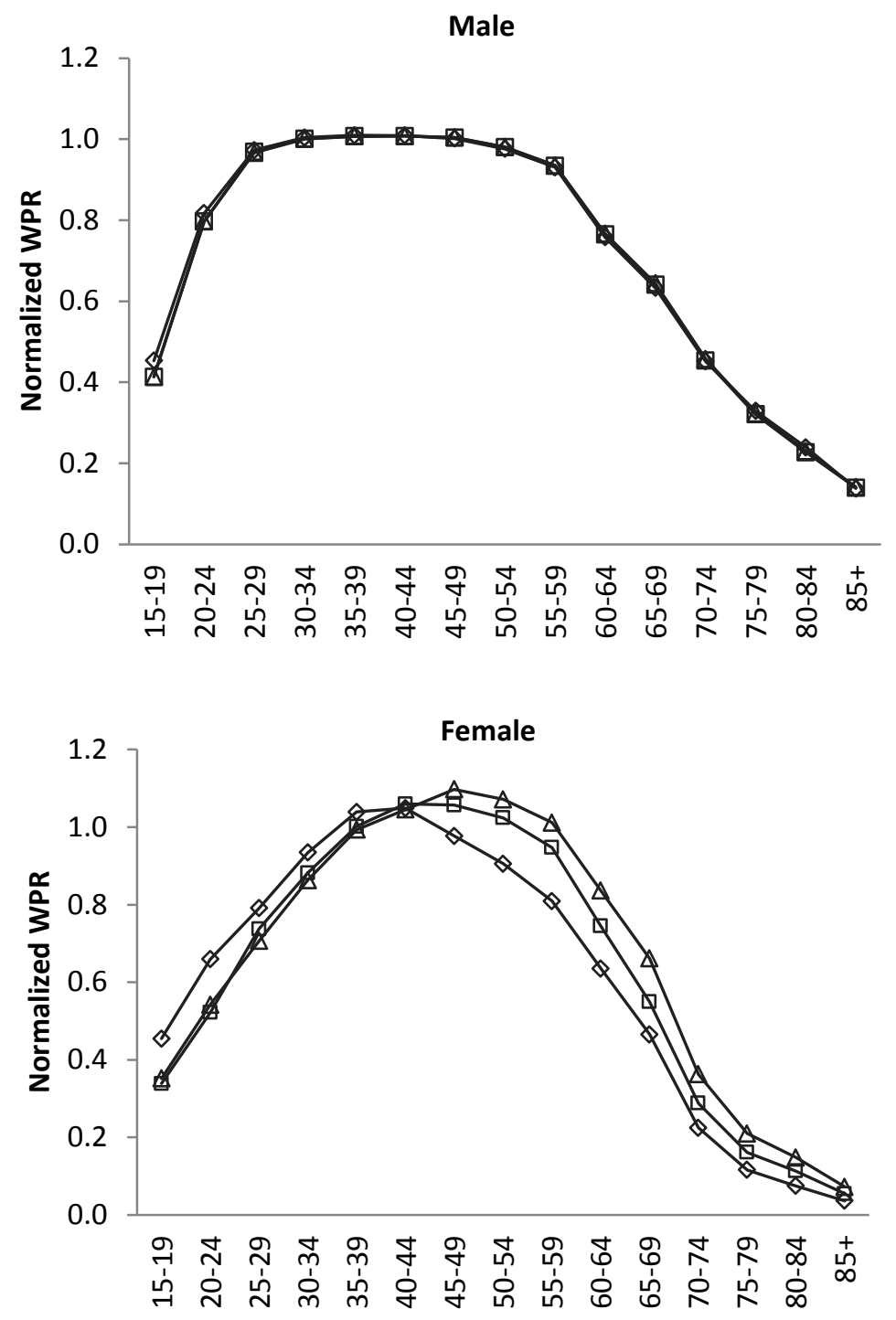

Age Group: $\longrightarrow 2010 \rightarrow 2030 \longrightarrow 2050$ 
Figure 1: (Continued)

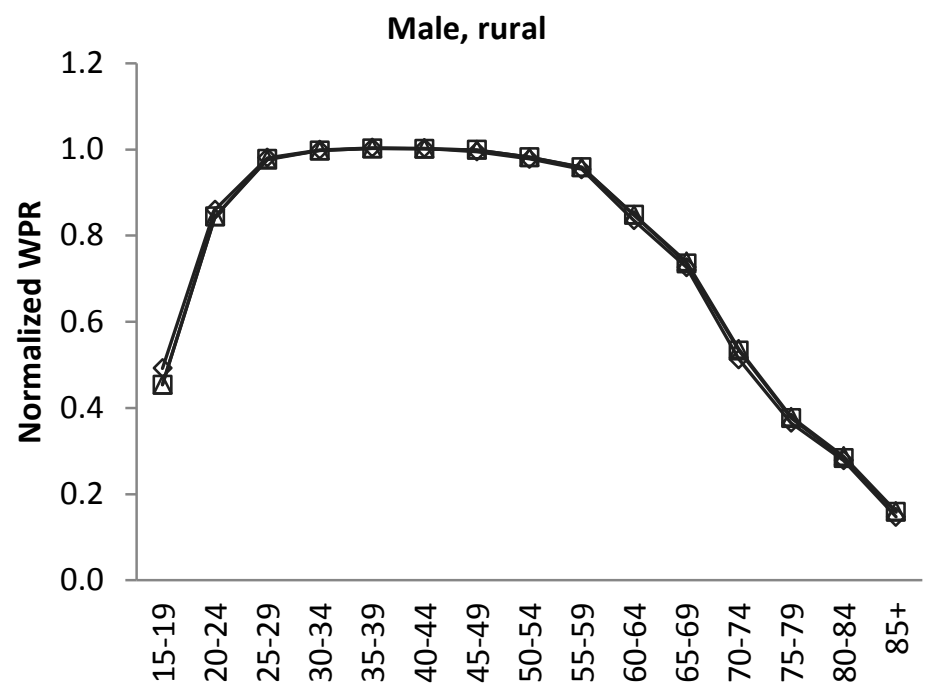

Female, rural

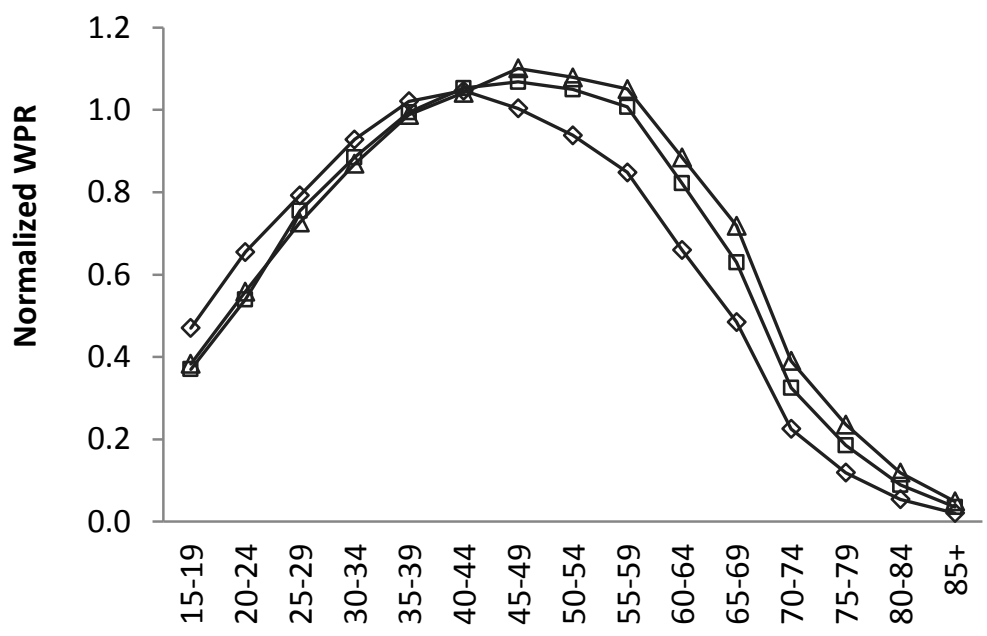

Age Group: $\longrightarrow 2010 \rightarrow-2030 \longrightarrow 2050$ 
Figure 1: (Continued)

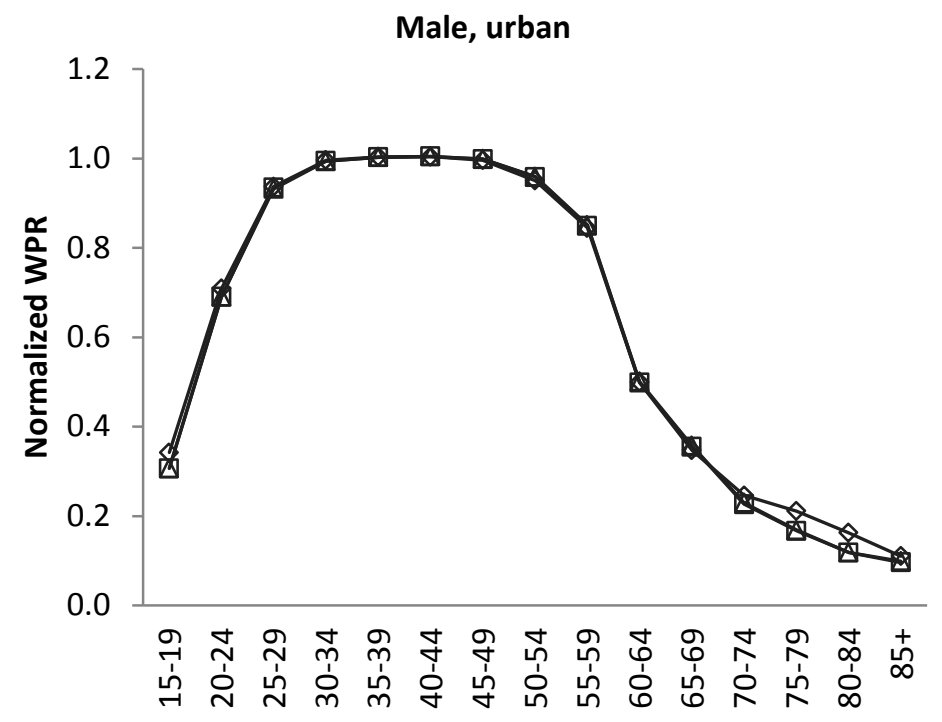

Female, urban

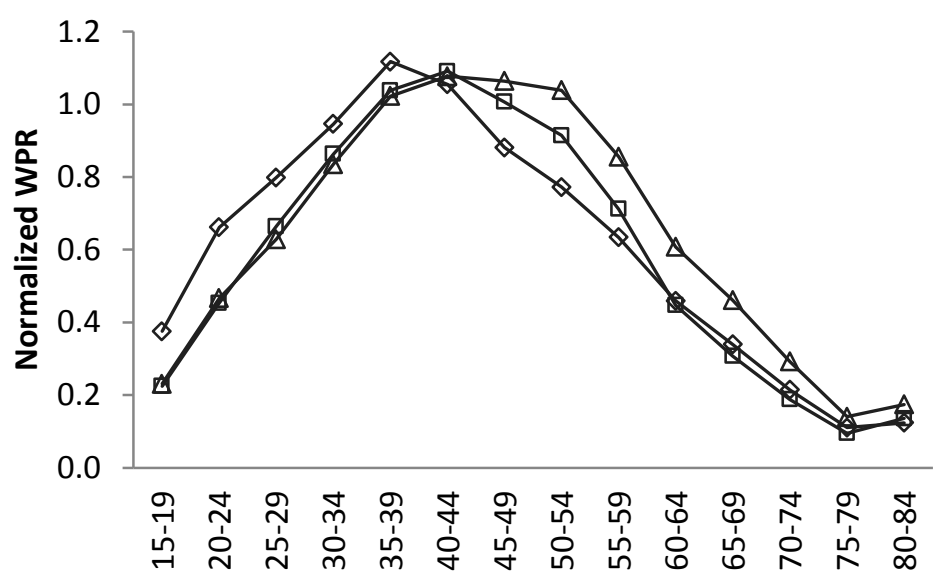

Age Group: $\quad \longrightarrow 2010 \rightarrow-2030 \rightarrow 2050$ 
Table 1: Projected work participation rates of elderly in India by broad age and sex, 2000-2050

\begin{tabular}{|c|c|c|c|c|c|c|c|}
\hline & & Age & 2010 & 2020 & 2030 & 2040 & 2050 \\
\hline \multirow[t]{19}{*}{ Total } & Male & $55-59$ & 91.0 & 91.2 & 91.6 & 91.7 & 91.7 \\
\hline & & $60-64$ & 74.1 & 74.6 & 75.0 & 75.2 & 75.2 \\
\hline & & $65-69$ & 61.9 & 62.7 & 62.8 & 63.1 & 63.2 \\
\hline & & $70-74$ & 44.1 & 44.2 & 44.5 & 44.8 & 44.8 \\
\hline & & $75-79$ & 32.1 & 31.0 & 31.4 & 31.5 & 31.7 \\
\hline & & $80-84$ & 23.4 & 22.2 & 22.3 & 22.4 & 22.5 \\
\hline & & $85+$ & 13.4 & 14.2 & 13.7 & 13.8 & 13.9 \\
\hline & & $15-59$ & 85.6 & 86.9 & 87.5 & 88.4 & 89.2 \\
\hline & & $60+$ & 56.2 & 57.4 & 55.9 & 55 & 54.3 \\
\hline & Female & $55-59$ & 45.3 & 50.3 & 56.9 & 58.3 & 58.5 \\
\hline & & $60-64$ & 35.6 & 39.1 & 44.7 & 47.4 & 48.3 \\
\hline & & $65-69$ & 26.1 & 29.7 & 33.0 & 37.3 & 38.2 \\
\hline & & $70-74$ & 12.6 & 15.7 & 17.3 & 19.8 & 21.0 \\
\hline & & $75-79$ & 6.5 & 8.5 & 9.7 & 10.7 & 12.1 \\
\hline & & $80-84$ & 4.2 & 5.4 & 6.8 & 7.5 & 8.6 \\
\hline & & $85+$ & 2.1 & 2.5 & 3.3 & 3.8 & 4.2 \\
\hline & & $15-59$ & 45.5 & 48.4 & 49.3 & 49.8 & 50 \\
\hline & & $60+$ & 22.2 & 25.6 & 27.6 & 29.3 & 29.6 \\
\hline & Total & $60+$ & 39.2 & 41.5 & 41.8 & 42.2 & 41.9 \\
\hline
\end{tabular}

\subsection{Projected life expectancy at age 60 years by sex}

We fit the Lee-Carter (1992) model using data on ASDRs from SRS (1971-2006) and apply model parameters 'a', 'b' and ' $k$ ' to forecast life expectancy separately for males and females up to 2050. These projected ASDRs are inputs for the construction of life tables and life expectancy with 95\% confidence intervals up to 2050. The projected and the past years life expectancy at age 60 years are shown in Figure 2. The solid lines are the expected trajectory of life expectancy at age 60 years for females and males, and the dotted lines surrounding each line are the corresponding $95 \%$ confidence interval of the life expectancies. Comparisons with SRS based life expectancy at age 60 years of RGI from 1973 to 2004 are also shown in the same figure. Past trends of life expectancy at age 60 years from the fitted Lee-Carter (1992) model are consistent with the available SRS figures with insignificant departure, and the precision of male projected life expectancy at age 60 years is higher than that of females. Anticipated life expectancy at age 60 both for males and females has shown appreciable gain. By 2050, male life 
expectancy at age 60 is expected to reach 21.2 years; however, for females it is 27.1 years for the same period.

Figure 2: Trends in life expectancy at age 60 in India compared with SRS abridged life table

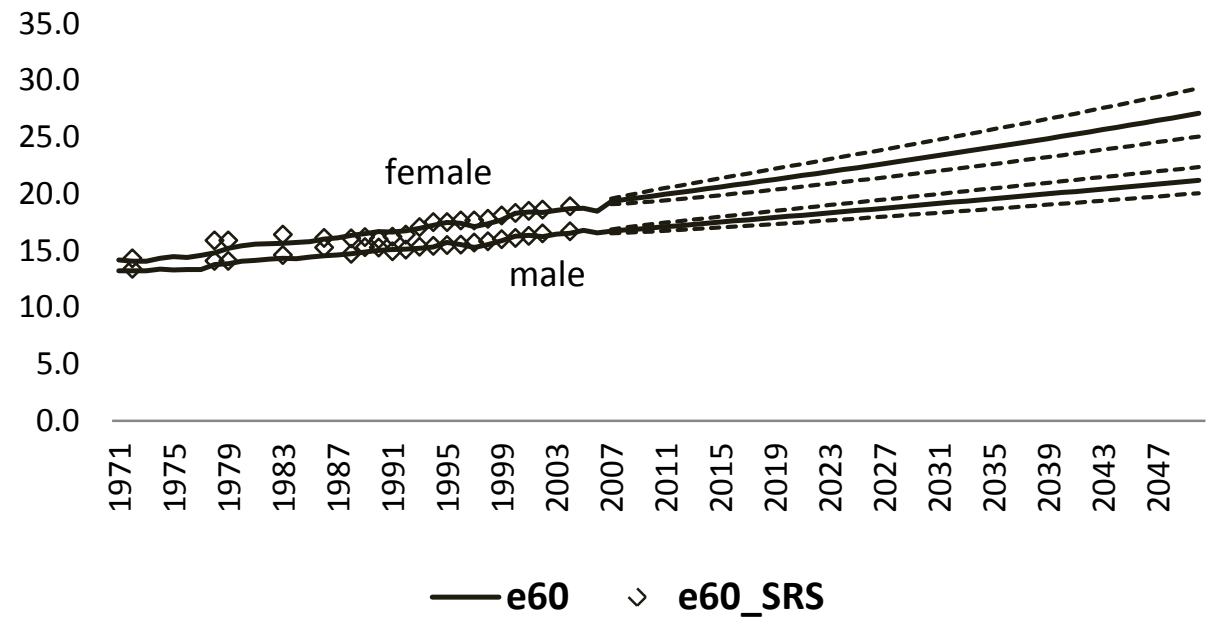

\subsection{Projected working life expectancy at age 60 years}

To examine whether or not longer life after age 60 years is translated into a longer period of work participation, we integrate the projected age-specific WPRs and projected life tables. We construct working life tables from 2010 to 2050 by linking Lx columns of projected life tables and projected WPRs. Figure 3 shows the projected trends WLE separately for males and females, to explore the average years of working life at ages 55 to 85 at intervals of 5 years. It also shows the ratio of WLE to life expectancy to demonstrate what percentage of the remaining average years of life is likely to be spent engaged in work. We refer to this as relative working life expectancy (RWLE). We find a marginal increase of 1.3 years in WLE at age 60 for males, i.e., from 8.7 in 2010 to 10 years in 2050. The pace of increase in WLE slows down as age advances: at age 70 years the expected gain is only 0.6 years (an increase from 3.7 to 4.3 years) and at age 80 years, expected gain in WLE is 0.4 years (from 1.3 to 1.7 years). RWLE at age 60 years, that is, the remaining years of working life as a 
percentage of the remaining life expectancy at age 60, a decline from 51.1 per cent in 2010 to 47.3 per cent in 2050 is projected for males. Similarly, at age 80, it is expected to decrease from 19 per cent to 18 per cent during the same period. This suggests that, among males, only a fraction of the prolonged life due to increase in old-age life expectancy can be translated into actual work participation, due to old-age related problems, including disability and geriatric health problems.

WLE at age 60 years for females is expected to increase by 5.2 years i.e. from 3.6 in 2010 to 8.8 years in 2050; at age 70 years, the increase is 2.8 years (from 1.0 to 3.8 years) and at age 80 years, it is 1.0 year (from 0.3 to 1.3 years). For females, RWLE at age 60, unlike that of males, shows an increase from 18.3 per cent in 2010 to 28 per cent in 2050. Thus among females a longer part of remaining average life at old age could be converted to working life.

Figure 3: Projected working life expectancy and percentage of working life at older ages for India by sex
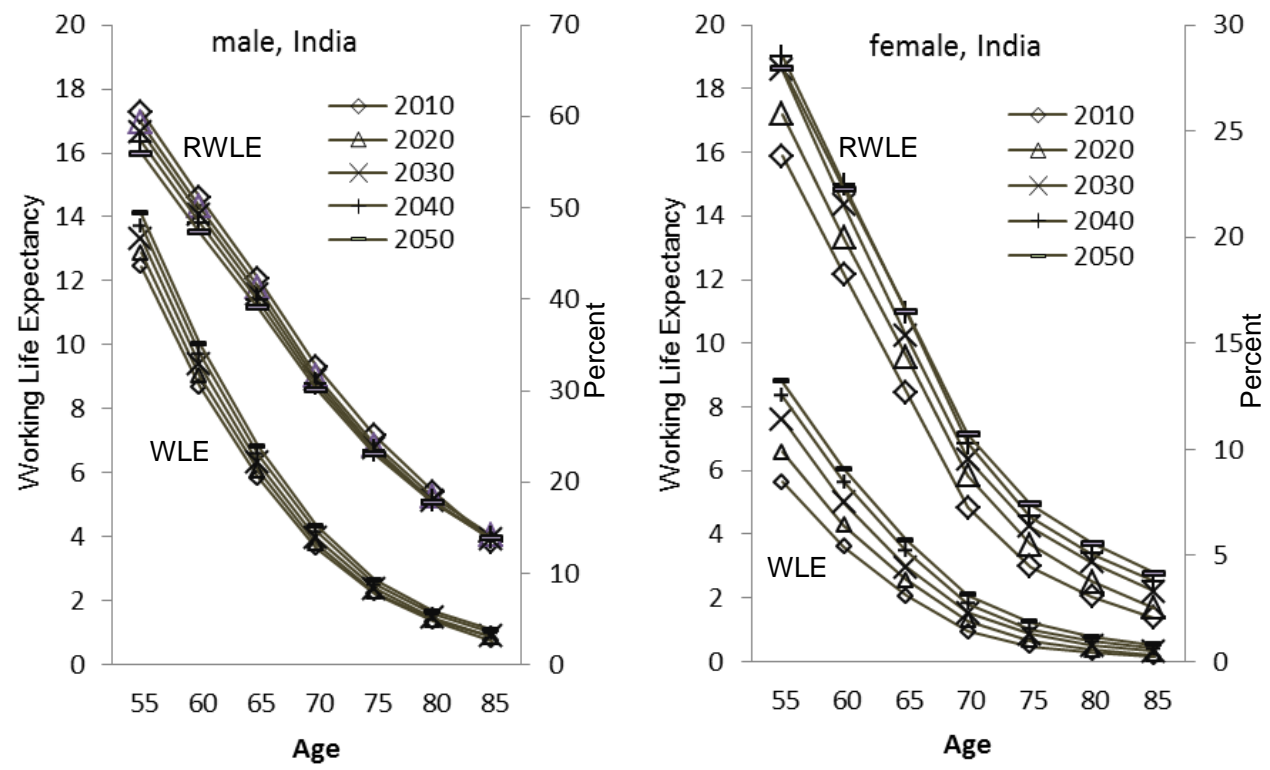

Figure 4 shows the trends of WLE and RWLE by place of residence. It reveals that WLE is likely to increase in both rural and urban areas. However, greater increases in 
WLE are expected among females, older adults and young elderly. Rural males show a clear decline in RWLE by the year of 2050. These declines disappear as age advances. However, RWLE among urban males may not show any change in the coming years. Female RWLE is expected to increase in both rural and urban areas, but by the year 2030 it will be stagnant.

WLE among rural males will increase from 10 years in 2010 to 12 years in 2050, and for rural females, it is likely to increase from four years in 2010 to seven years in 2050. Further, in urban areas male WLE is expected to increase from 10 years to 11 years, while the corresponding increase for females is from four years to seven years. In rural areas, RWLE shows a decline from 58 to 53 per cent for males and an increase from 22 to 25 per cent for females. For urban residents, it will go down from 57 to 56 per cent for males and increase from 22 to 29 per cent for females during 2010-50.

Therefore, rural-urban trends do not reveal a significant difference by place of residence in length of working life; however, greater increase in urban female RWLE suggests diminishing gender gaps in work participation in urban areas in the coming years, due to increasing opportunities for women, as mentioned earlier.

Figure 4: Projected working life expectancy and percentage of working life at older ages for India by sex and place of residence
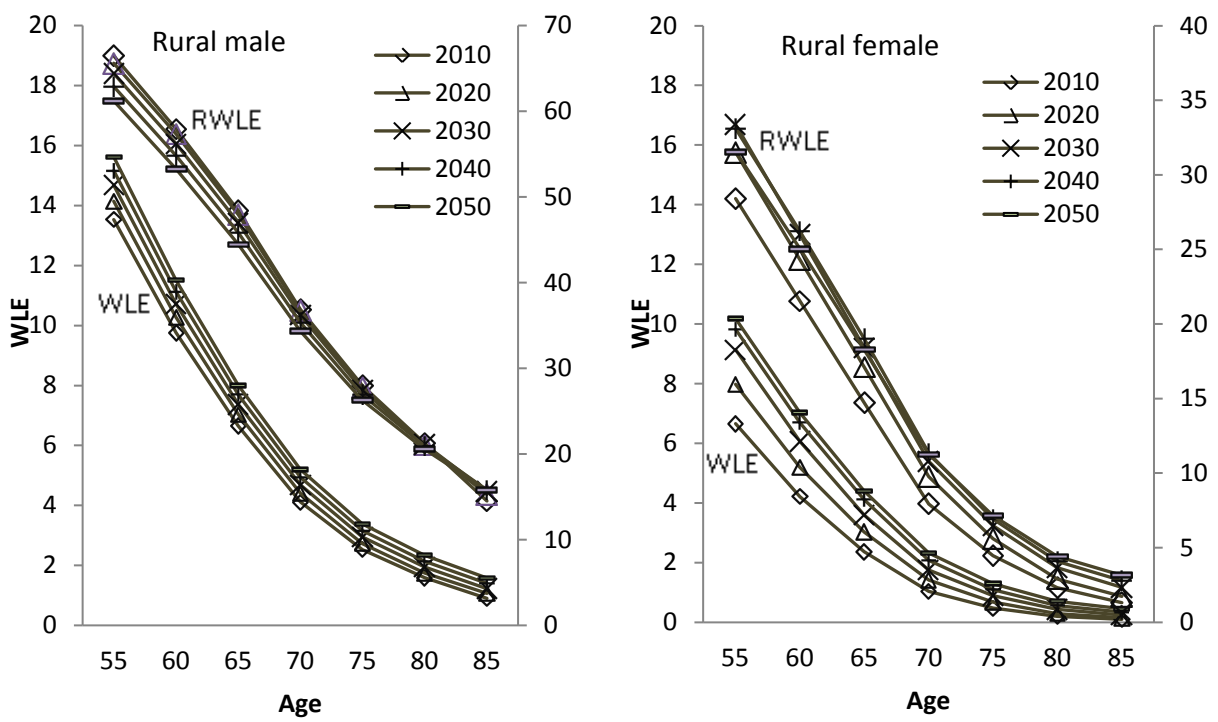
Figure 4: (Continued)
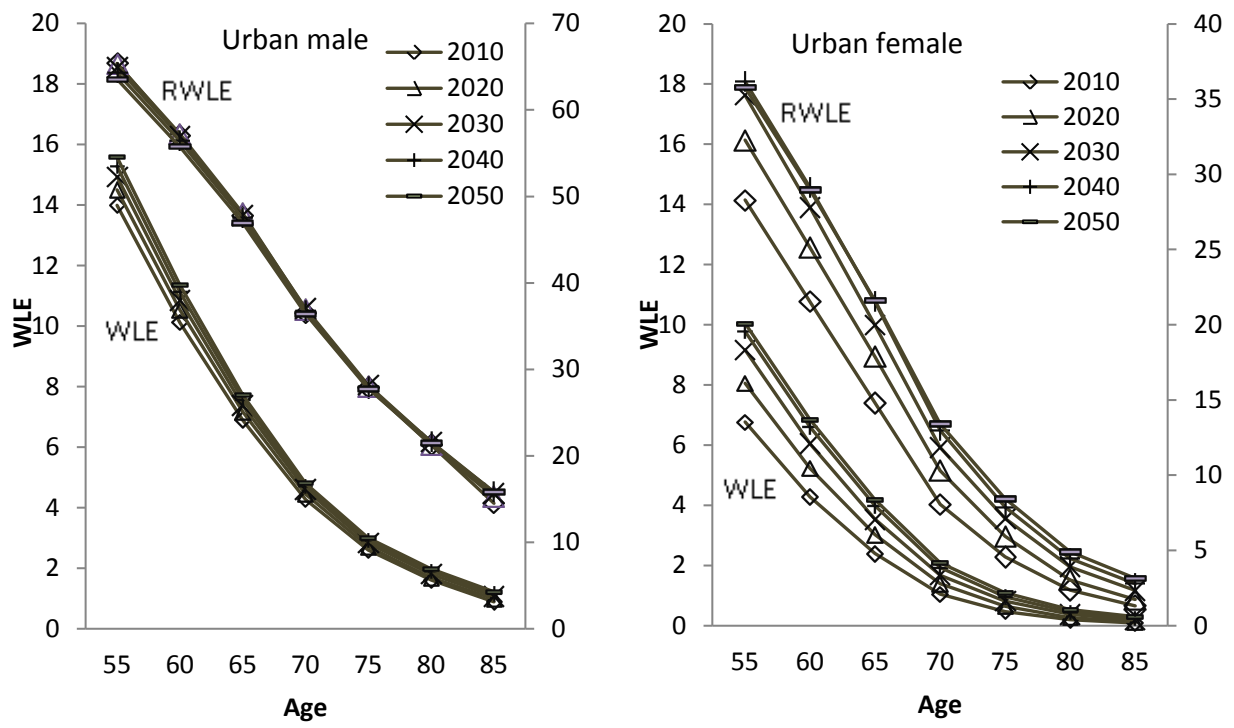

The results of this section reflect the interplay of changing age distribution, age patterns of work participation of recent cohorts, and expected enhancement in life expectancy at old age. This can change, depending on alteration in retirement policy for the formal sector and change in social assistance schemes for the informal sector. However, as noted earlier, it is doubtful that such change will happen in India, at least for few decades. With the expected shrinking of the working population after 2035 (Ladusingh and Narayana 2011b), retirement age, which varies from 55 to 65 years across states in India (Rajan 2010), could increase to compensate for the shortage of the working population. Forman and Chen (2008) have highlighted the adjustment of retirement age for the increase in life expectancy.

\subsection{Old age dependency ratio adjusted for work participation}

The conventional ODR is the ratio of the population aged 60 years and above as to the population in the working age group 15-59 years. In this paper, we proposed that work participation AODR be computed by considering only the non-working older people in the numerator and working people in the age group of 15-59 years in the denominator of the conventional measure. Column (a) of Table 2 shows conventional ODR for males 
and females as well as combined ODR. Old age dependency will increase by 19.2 per cent from 12.2 per cent in 2010 to 31.4 per cent in 2050. When the combined ODR is disaggregated by sex, keeping the denominator as the total population in the working age group 15-49 years, ODR for females is persistently higher than that for males throughout the projection period 2010-50. This indicates higher contribution from old age females in the combined ODR. Column (b) shows ODR adjusted for WPRs among old age and 15-59 year age groups. Though an increase in the female WPR at old ages is projected, the increase each year is much lower than that for males. As such, the projected level of AODR for females is higher than the conventional ODR. On the other hand, as the male WPRs are higher, AODRs for males are lower than the corresponding conventional ODR. The combined AODR, measuring the old age dependents as a percentage of prime age workers captures not only the age structure of the population, but also the WPRs at old ages, and is a preferable measure of ODR.

Table 2: $\quad$ Projected old age dependency ratio by sex for India, 2010-50

\begin{tabular}{|c|c|c|c|c|c|c|c|c|}
\hline \multirow[t]{2}{*}{ Year } & \multicolumn{3}{|c|}{ (a) old age dependency ratio } & \multicolumn{3}{|c|}{$\begin{array}{l}\text { (b) adjusted old age } \\
\text { dependency ratio }\end{array}$} & \multicolumn{2}{|c|}{$\begin{array}{l}\text { (c) proportion of } \\
\text { dependency by sex }\end{array}$} \\
\hline & female & male & total & female & male & total & F/total & M/total \\
\hline 2010 & 6.4 & 5.8 & 12.2 & 7.5 & 3.9 & 11.4 & 0.66 & 0.34 \\
\hline 2015 & 7.2 & 6.6 & 13.8 & 8.1 & 4.2 & 12.3 & 0.66 & 0.34 \\
\hline 2020 & 8.1 & 7.4 & 15.5 & 8.8 & 4.6 & 13.4 & 0.66 & 0.34 \\
\hline 2025 & 9.0 & 8.2 & 17.3 & 9.7 & 5.2 & 14.9 & 0.65 & 0.35 \\
\hline 2030 & 10.1 & 9.1 & 19.2 & 10.6 & 5.8 & 16.4 & 0.64 & 0.36 \\
\hline 2035 & 11.3 & 10.2 & 21.4 & 11.6 & 6.5 & 18.1 & 0.64 & 0.36 \\
\hline 2040 & 12.7 & 11.5 & 24.2 & 12.9 & 7.4 & 20.3 & 0.64 & 0.36 \\
\hline 2045 & 14.5 & 13.0 & 27.6 & 14.6 & 8.4 & 23.0 & 0.63 & 0.37 \\
\hline 2050 & 16.6 & 14.9 & 31.4 & 16.6 & 9.7 & 26.3 & 0.63 & 0.37 \\
\hline
\end{tabular}

Note: Column (c): female AODR/total AODR and male AODR/total AODR.

To see the gender gap in AODR more vividly, the proportional share of females and males in the total AODR are shown in column (c). All through the projection period 2010-50, males contribute 25 to 30 per cent of the total AODR, while the remaining 70 to 75 per cent is contributed by females. However, from 2030 onwards, female AODR declines by 10 per cent while male AODR increases by the same percentage because of their complementary nature. 


\subsection{Projected old age dependency adjusted for work participation by states}

Table 3 shows the projected trends of old age dependency by state, in terms of ODR. In 2005, Kerala has the highest ODR with 17 persons aged 60 years and above for every 100 persons in the working age group 15-59 years. Tamil Nadu, Himachal Pradesh, Punjab and Maharashtra are other states with a high ODR at 15.2, 14.9, 14.4, and 13.7 per cent respectively, whereas Delhi and the North-Eastern states have ODR of less than 10 per cent. By the year 2025, ODR will increase in all states, but the increase is most pronounced in the states of Kerala, Tamil Nadu, West Bengal, Karnataka, Andhra Pradesh and Gujarat. ODR adjusted for age-specific WPRs is found to be highest in Kerala followed by Punjab, Delhi, West Bengal and Tamil Nadu where AODR is above 14 per cent during 2005. In 2025, 12 states will have AODR above 14 per cent and, strikingly, Kerala will have AODR of 34.

Table 3: $\quad$ Projected old age dependency ratios (\%) for major states in India, 2005-50

\begin{tabular}{lrrrrrrrrrr}
\hline \multicolumn{1}{c}{ State } & \multicolumn{2}{c}{$\mathbf{2 0 0 5}$} & \multicolumn{2}{c}{$\mathbf{2 0 1 0}$} & \multicolumn{2}{c}{ 2015 } & \multicolumn{2}{c}{ 2020 } & \multicolumn{2}{c}{$\mathbf{2 0 2 5}$} \\
& ODR & \multicolumn{1}{c}{ AODR } & ODR & AODR & ODR & AODR & ODR & AODR & ODR & AODR \\
\hline Uttarakhand & 13.3 & 9.2 & 13.8 & 7.8 & 15.0 & 7.3 & 16.5 & 7.8 & 18.3 & 8.7 \\
Jharkhand & 10.2 & 9.2 & 11.4 & 9.3 & 13.0 & 9.6 & 15.1 & 10.0 & 17.5 & 10.8 \\
Uttar Pradesh & 12.0 & 10.7 & 12.3 & 10.6 & 13.1 & 10.6 & 14.5 & 10.8 & 16.0 & 11.4 \\
Himachal Pradesh & 14.9 & 8.9 & 15.8 & 9.3 & 17.4 & 10.0 & 19.7 & 11.0 & 22.5 & 12.4 \\
Chhattisgarh & 12.2 & 9.5 & 12.9 & 9.8 & 14.0 & 10.4 & 15.8 & 11.4 & 18.2 & 12.9 \\
Assam & 9.5 & 10.5 & 10.2 & 10.1 & 11.6 & 10.4 & 13.9 & 11.3 & 17.0 & 13.0 \\
Rajasthan & 11.7 & 10.1 & 12.2 & 10.3 & 13.1 & 10.8 & 14.7 & 11.7 & 16.8 & 13.1 \\
Madhya Pradesh & 11.6 & 9.8 & 11.8 & 10.1 & 12.6 & 10.6 & 14.1 & 11.6 & 16.3 & 13.4 \\
Haryana & 11.8 & 13.5 & 11.9 & 12.3 & 12.8 & 12.1 & 14.7 & 12.6 & 17.1 & 13.7 \\
Other North East & 9.8 & 9.8 & 11.0 & 10.0 & 12.7 & 10.5 & 15.5 & 11.7 & 18.8 & 13.8 \\
Maharashtra & 13.7 & 12.7 & 14.0 & 12.7 & 15.0 & 13.2 & 17.1 & 14.5 & 19.7 & 16.5 \\
Karnataka & 12.7 & 12.2 & 14.1 & 13.1 & 16.2 & 14.4 & 19.0 & 16.2 & 22.2 & 18.5 \\
Andhra Pradesh & 12.6 & 11.5 & 13.8 & 12.7 & 15.7 & 14.3 & 18.4 & 16.5 & 21.7 & 19.6 \\
Jammu \& Kashmir & 11.2 & 11.0 & 12.1 & 12.2 & 13.8 & 13.9 & 16.1 & 16.5 & 18.8 & 19.9 \\
Orissa & 13.4 & 13.6 & 14.0 & 14.2 & 15.4 & 15.4 & 17.9 & 17.3 & 21.2 & 20.2 \\
Punjab & 14.4 & 15.6 & 14.9 & 15.4 & 16.5 & 16.1 & 19.1 & 17.8 & 22.1 & 20.6 \\
Bihar & 11.4 & 12.0 & 12.2 & 13.8 & 13.2 & 15.3 & 15.0 & 17.6 & 17.1 & 20.7 \\
Gujarat & 11.8 & 11.9 & 13.0 & 13.2 & 15.0 & 15.0 & 17.7 & 17.4 & 20.9 & 20.7 \\
West Bengal & 11.8 & 14.8 & 12.9 & 15.5 & 14.8 & 16.9 & 17.8 & 19.6 & 21.6 & 23.3 \\
Tamil Nadu & 15.2 & 14.4 & 17.0 & 15.8 & 19.6 & 17.9 & 22.7 & 20.3 & 26.6 & 23.6 \\
Delhi & 8.5 & 15.2 & 9.4 & 17.0 & 10.7 & 19.5 & 12.7 & 22.6 & 14.8 & 26.3 \\
Kerala & 17.3 & 20.6 & 18.9 & 22.3 & 21.6 & 25.1 & 24.9 & 28.9 & 29.0 & 33.9 \\
\hline
\end{tabular}

Note: ODR: Old age dependency ratio, AODR: adjusted old age dependency ratio. "Excluding Assam 
Analysis by state reveals that, after adjustment of age-specific WPRs, old age dependency changes significantly and is found to be lower than the conventional ODR in most of the states, which is in accordance with results of the study by Bhagat and Unisa (2006). However, a few states, such as Kerala, Delhi, West Bengal, Bihar and Jammu \& Kashmir show higher AODR compared to the conventional one. Strikingly, in 2025, the more urbanized states, namely, Kerala, Delhi, Tamil Nadu, West Bengal and Gujarat will have more than one elderly dependent on every five working persons in the age group 15-59 years. On the other hand, the hilly states of Uttarakhand and Himachal Pradesh and Assam show lower dependency ratios indicating longer period of work participation of elderly in these states.

Moreover, WLE by state reveals that Kerala had only 24 per cent $^{3}$ of remaining years of working life at age 60 in 2001, whereas Uttar Pradesh had 51 per cent ${ }^{1}$,the highest state percentage. More urbanized or developed states will have fewer years of working life and higher dependency ratios in the future, which, in one way, may be a negative sign for longer active life and ageing. The available literature on recent trends suggests the expansion of morbidities in older age, which may discourage longer working life. On the other hand, it may be a positive sign with regard to ageing if people engage in the organized employment sector and retire with sufficient savings and pension for their older ages. Therefore, there is a strong need to strengthen human capital with health and education, encourage saving behaviour, increase financial literacy and strengthen social security for older ages.

These AODRs are calculated separately for males and females, and the ratio of female AODR to total AODR is shown in Table 4. This gives an idea of future share of females in the total old age dependency. Sex differentials are higher in the states of Bihar, Jammu \& Kashmir and Chhattisgarh and lower in Delhi, Haryana, Tamil Nadu and Maharashtra in 2005. In the year 2025, Bihar, Jammu \& Kashmir and Himachal Pradesh show the highest sex differentials in AODR and Delhi, Jharkhand, NorthEastern states (excluding Assam) and Maharashtra show the least. In addition, over the period, most of the states show a diminishing trend in sex differentials in AODR except the states of Bihar, Jammu \& Kashmir, Himachal Pradesh, Assam and Madhya Pradesh.

\footnotetext{
${ }^{3}$ The figure is calculated as WLE/LE*100 from Table no. 3, pp. 69. (Dhillon and Ladusingh, 2011),
} 
Table 4: Projected ratio of female to male adjusted old age dependency by states

\begin{tabular}{llllll}
\hline & $\mathbf{2 0 0 5}$ & $\mathbf{2 0 1 0}$ & $\mathbf{2 0 1 5}$ & $\mathbf{2 0 2 0}$ & $\mathbf{2 0 2 5}$ \\
\hline Bihar & 0.72 & 0.71 & 0.71 & 0.72 & 0.73 \\
Jammu \& Kashmir & 0.71 & 0.70 & 0.71 & 0.71 & 0.72 \\
Himachal Pradesh & 0.65 & 0.65 & 0.67 & 0.69 & 0.70 \\
Assam & 0.66 & 0.67 & 0.68 & 0.69 & 0.68 \\
Madhya Pradesh & 0.67 & 0.67 & 0.67 & 0.68 & 0.68 \\
Chhattisgarh & 0.70 & 0.69 & 0.69 & 0.68 & 0.68 \\
Rajasthan & 0.68 & 0.66 & 0.66 & 0.66 & 0.66 \\
Gujarat & 0.67 & 0.67 & 0.66 & 0.66 & 0.65 \\
West Bengal & 0.65 & 0.65 & 0.64 & 0.63 & 0.63 \\
Kerala & 0.69 & 0.67 & 0.65 & 0.63 & 0.63 \\
Punjab & 0.62 & 0.61 & 0.61 & 0.61 & 0.62 \\
Uttar Pradesh & 0.68 & 0.65 & 0.64 & 0.63 & 0.62 \\
Orissa & 0.66 & 0.64 & 0.63 & 0.62 & 0.62 \\
Uttarakhand & 0.65 & 0.63 & 0.61 & 0.60 & 0.62 \\
Andhra Pradesh & 0.63 & 0.62 & 0.62 & 0.61 & 0.61 \\
Tamil Nadu & 0.61 & 0.61 & 0.60 & 0.60 & 0.61 \\
Karnataka & 0.63 & 0.63 & 0.62 & 0.61 & 0.60 \\
Haryana & 0.60 & 0.61 & 0.61 & 0.60 & 0.59 \\
Maharashtra & 0.62 & 0.60 & 0.59 & 0.58 & 0.58 \\
Other North East & 0.64 & 0.61 & 0.59 & 0.58 & 0.57 \\
Jharkhand & 0.67 & 0.62 & 0.59 & 0.55 & 0.52 \\
Delhi & 0.53 & 0.52 & 0.50 & 0.50 & 0.50 \\
\hline
\end{tabular}

\subsection{Validating projections with the recent survey of NSS (2009-10)}

We validate age-specific projections using the recent survey of NSS (2009-10) and find that women's WPR surprisingly declined between 2004-05 and 2009-10 in all age groups. This is in contrast to our projected figure for the year 2010; however, the difference in projected and actual participation rates is not large in older ages among women and all ages for males. The survey (NSS 2011) results have already generated debate on the reasons behind declining female WPRs.

Projections suggest increasing female WPRs, as in recent decades, trends of female participation have shown continuous increase. Young women who have entered in the workforce may continue to work in the future, and this is likely to increase future old age WPR among women. However, in view of the recent economic slowdown, the central government is focusing on austerity measures to bring the economy back on 
track. Under these circumstances, the unorganized sector in India is likely to remain dominant. Creation of jobs by the state and central governments have been stalled for decades, except for expansion in the corporate sector, where more jobs should become available, especially for women. Further, Government policies may encourage the generation of female-friendly jobs in the market to take advantage of demographic dividends in the country.

\section{Summary and conclusion}

The present study is an attempt to address the question of whether longer life expectancy in India would translate into longer working life. The methodology involves the projection of age-specific WPRs and ASDRs, then integrating them to construct working life tables, to assess WLE at age 60. For the projection of age-specific WPRs, the study adopts the cohort entry and exit method (Burniaux et al. 2003), and for the projection of ASDR it applies the Lee-Carter model (1992). The study does not indicate significant changes in the age pattern of WPRs during the projection period 2010-50. However, over time, female age patterns of work participation suggest marginal increase at old ages, even higher than those of the prime working age group. Regardless of sex, WPRs decreases with advancing age, and the WPRs among males are much higher than that of their female counterparts.

In terms of average years of remaining working life at age 60, males are expected to continue working for 8.7 years on the average in 2010 which is likely to reach 10 years in 2050 while the corresponding figures for females are 3.6 and 8.8 years respectively. It is important to keep in mind that though female life expectancy at age 60 is higher than that of males, their WPRs are much lower. However, in terms of RWLE at age 60, which is an expression of percentage of remaining life expectancy converted into working years, females have an edge over males. Therefore, it can be said that future improvement in longevity may not translate into longer working life for males as much as for females. This is in agreement with other research findings, as in response to economic development, people have a tendency to save more money during their prime working age and withdraw earlier from work (Ozcan et al. 2005). Past trends of work participation and WLE at older ages have been observed by Dhillon and Ladusingh (2011) using Indian Census and SRS data. This study observed that elderly WPR has declined from 43.2 to 40.3 per cent over all, from 1971- 2001. While it declined from 73.8 to 65.8 per cent for males, it increased from 10.5 to 20.9 per cent for females during the same period. It also found that among females, longevity is translating into longer economically active lives, but this is not the case for males. 
Further, a look at the rural-urban differential in average years of work participation relative to average years of remaining life among the elderly shows a decline in the increase of the working period relative to the increase in life expectancy among rural males, whereas this ratio remains more or less stable over time among urban males. On the other hand, for females, there is a relative increase in working years with the increase in life expectancy regardless of place of residence. However, the increase in urban areas is more pronounced than in rural areas. Therefore, it is concluded that in urban areas improvement in longevity supports longer working life, but the same is not true for rural areas.

To overcome the deficiencies of the conventional ODR in this study, we adjusted ODR for age-specific WPRs. Kerala, Delhi, Tamil Nadu, West Bengal and Gujarat showed very high old age dependency in 2025. On the other hand, the hilly states of Uttarakhand, Himachal Pradesh and Assam showed a lower dependency ratio, indicating higher participation by the elderly in economic activities. We conclude that the conventional ODR overestimates the burden of old age population on the working population in most of the states in India. This study predicts that, in the coming decades, AODR is likely to increase, particularly among females, because of the current low WPR and higher growth among females as compared their male counterparts. Therefore, the dependency arising from old age population growth among females can be countered by creating more female-friendly jobs, particularly in hospitality and service sectors, thereby increasing female WPRs.

\section{Acknowledgements}

The authors are grateful to two anonymous referees for their comments and suggestions, which have led to considerable improvement of the paper. 


\section{References}

Arokiasamy, P., Bloom, D., Lee, J., Feeney, K., and Ozolins, M. (2011). Longitudinal aging study in India: Vision, design, implementation, and some early results. Harvard: Center for population and development studies. (PGDA Working Paper No. 82). http://www.hsph.harvard.edu/pgda/working.html.

Audinarayana, N. (2001). Factors affecting the work participation of elderly: An empirical investigation. Demography India 30(1): 61-72.

Australian Government Productivity Commission (2005). Economic implications of an ageing Australia. Canberra: Productivity Commission Research Report.

Bhagat, R.B. and Unisa, S. (2006). Ageing and dependency in India: A new measurement. Asian Population Studies 2(2): 201-214. doi:10.1080/17441730 600923133.

Booth, H. and Tickle, L. (2003). The future aged: New projections of Australia's elderly population. Australasian Journal on Ageing 22(4): 196-202. doi:10.1111/ j.1741-6612.2003.tb00497.x.

Boskin, M.J. (1977). Social security and retirement decisions. Economic Inquiry 15(1): 1-25. doi:10.1111/j.1465-7295.1977.tb00446.x.

Buettner, T. (2002). Approaches and experiences in projecting mortality patterns for the oldest old. North American Actuarial Journal 6(3): 14-25. doi:10.1080/1092 0277.2002.10596053.

Burniaux J.-M., Duval, R., and Jaumotte, F. (2003). Coping with ageing: A dynamic approach to quantify the impact of alternative policy options on future labour supply in OECD countries. Paris: OECD. (Economics Department Working Paper No. 371).

Carter L.R. and Lee, R.D. (1992). Modeling and forecasting US sex differentials in mortality. International Journal of Forecasting 8(3): 393-411. doi:10.1016/016 9-2070(92)90055-E.

Crawford, V.P. and Lilien, D.M. (1981). Social security and the retirement decision. Quarterly Journal of Economics 96(3): 505-529. doi:10.2307/1882684.

Dandekar, K. (1996). The Elderly in India. New Delhi: Sage Publication.

Dhillon, P. and Ladusingh, L. (2011). Economic activity in post retirement life in India. Asia-Pacific Population Journal. 26(3): 55-71. 
Forman J.B. and Chen Y.P. (2008). Optimal Retirement Age. Paper presented at the 2008 Retirement 20/20 Conference Defining the Characteristics of the 21st Century Retirement System Crystal Gateway Marriot, Washington, DC November 17-18, 2008. www.soa.org.

Gore, M.S. (1992). Aging and the future of the human being. The Indian Journal of Social Work 53(2): 210-211.

Gulati, L.and Rajan, S.I.. (1991). Population aspects of aging in Kerala: Their economic and social context. Trivandrum, Kerala (India): Centre for Developement Studies Monographs.

Harrower, S. (2007). British Columbia labour force participation rate projections to 2031. Victoria, BC: Ministry of Labour and Citizen's Services. http://www.bcstats.gov.bc.ca/Publications/AnalyticalReports.aspx

International Labour Organization (2009). Estimates and projections of the economically active population: 1980-2020 (Fifth edition). Geneva: ILO. http://laborsta.ilo.org/applv8/data/EAPEP/v6/ILO_EAPEP_methodology_2009. pdf

Kim, J. (2010). Past and future of the labor force in emerging Asian economies. Manila: Asian Development Bank. (ADB Economics Working Paper Series No. 218). http://www.adb.org/documents/working-papers/2010/economics-wp218.pdf

Krishnan, P. (1977). The length of working life: India, 1971. Journal of the Royal Statistical Society, Series A (General) 140(3): 359-365. doi:10.2307/2344926.

Krzysztof H., Behrendt, C., and Hagemejer, K. (2009). Can low-income countries afford basic social security? Paris: OECD. (OECD Publication Promoting ProPoor Growth). http://www.oecd.org/dataoecd/26/20/43280726.pdf.

Kumar, A. and Anand, N. (2006). Poverty target programs for the elderly in India with special reference to National Old Age Pension Scheme, 1995. Manchester, UK: Chronic Poverty Research Centre. (Working Paper No. 2008-09) doi:10.2139/ssrn.1755099.

Kundu, A. and Mohanan, P.C. (2008). Employment and inequality outcomes in India. Paris: OECD. http://www.oecd.org/els/emp/42546020.pdf.

Ladusingh, L. and Narayana, M.R. (2011a). The role of familial transfers in supporting life cycle deficit in India. In: Lee, R. and Mason, A. (eds.). Population Aging and the Generational Economy: A Global Perspective. Cheltenham, UK: Edward Elgar Publishing. 
Ladusingh, L. and Narayana, M.R. (2011b). Demographic dividends for India: Evidence and implications based on national transfer accounts. Manila: Asian Development Bank. (ADB Economics Working Paper No. 292). http://www.adb.org/publications/demographic-dividends-india-evidence-andimplications-based-national-transfer-accounts?ref=data/publications.

Lee, R.D. and Carter, L.R. (1992). Modeling and forecasting US mortality. Journal of the American Statistical Association 87(419): 659-671. doi:10.2307/2290201.

Lilien, D.M. (1982). Sectoral shifts and cyclical unemployment. Journal of Political Economy 90(4): 777-793. doi:10.1086/261088.

Mohanty, S.K. and Sinha, R.K. (2010). Deprivation among the elderly in India. In Alam, M. and Barrientos, A. (eds.). Demographics, employment and old age security- Emerging trends and challenges in South Asia. New Delhi: Macmillan Publishers India Ltd.

Narayana, M.R. (2011). Lifecycle deficit and public age reallocations for India's elderly population: Evidence and implications based on National Transfer Accounts. Journal of Population Ageing 4(4): 207-230. doi:10.1007/s12062-011-9044-6.

National Sample Survey Organization (2006). Employment and Unemployment Situation in India 2004-05 (Part - I). New Delhi: Ministry of Statistics \& Programme Implementation, Government of India. http://mospi.nic.in/ Mospi_New/Admin/publication.aspx.

National Sample Survey Organization (2011) Employment and Unemployment Survey 2009-10. New Delhi: Ministry of Statistics \& Programme Implementation, Government of India. http://mospi.nic.in/Mospi_New/Admin/publication.aspx.

Nurminen, M., Heathcote, C., and Davis, B., (2005). Working life expectancies of ageing Finnish workers in the municipal sector. The Internet Journal of Epidemiology 2 (1). doi:10.5580/14b5.

Ozcan, S.K and Weil, D.N. (2005). Mortality change, the uncertainty effect, and retirement. (NBER Working Paper No. 8742). Cambridge, MA: NBER.

Planning Commission; Government of India (2008). Eleventh Five Year Plan (20072012). Volume I: Inclusive Growth. New Delhi: Oxford University Press.

Quinn, J.F. (1977). Microeconomic determinants of early retirement: A cross-sectional view of white married men. Journal of Human Resources 12(3): 329-346. doi:10.2307/145494. 
Dhillon \& Ladusingh: Working life gain from gain in old age life expectancy in India

Rajan, S.I. (2010). Demographic ageing and employment in India. Bangkok: International Labour Organization, Regional Office for Asia and the Pacific.(ILO Asia-Pacific Working paper series).

Rajan, S.I., Mishra, U.S., and Sharma, P.S. (1999). India's Elderly: Burden or Challenge? New Delhi: Sage Publication.

Sanderson, W.C. and Scherbov, S. (2005) Average remaining lifetimes can increase as human populations age. Nature 435: 811-813. doi:10.1038/nature03593.

Sanderson, W.C. and Scherbov, S. (2010). Remeasuring Aging. Science 329(5997): 1287-1288. doi:10.1126/science.1193647.

Schrier, D. (2010). British Columbia labour force participation rates projections: A cohort analysis model. Victoria, BC: Ministry of Labour and Citizen’s Services. http://www.bcstats.gov.bc.ca/Publications/AnalyticalReports.aspx

Skirbekk, V., Loichinger, E., and Weber, D. (2012). Variation in cognitive functioning as a refined approach to comparing ageing across countries. Proceedings of the National Academy of Sciences 109(3): 770-774. doi:10.1073/pnas.1112173109.

Sullivan, D.F. (1971). A single index of mortality and morbidity. HSMHA Health Reports 86(4): 347-354. doi:10.2307/4594169.

Uppal, S. and Sarma, S. (2007). Aging, health, and labor market activity: The case of India. World Health and Population 9(4): 79-97.

Vodopivec, M. and Arunatilake, N. (2008). Population aging and the labor market: The case of Sri Lanka. Washington, DC: The World Bank. (SP Discussion Paper No. 0821). 


\section{Appendix}

Figure (a): Entry-Exit rates by age between 2000 and 2005

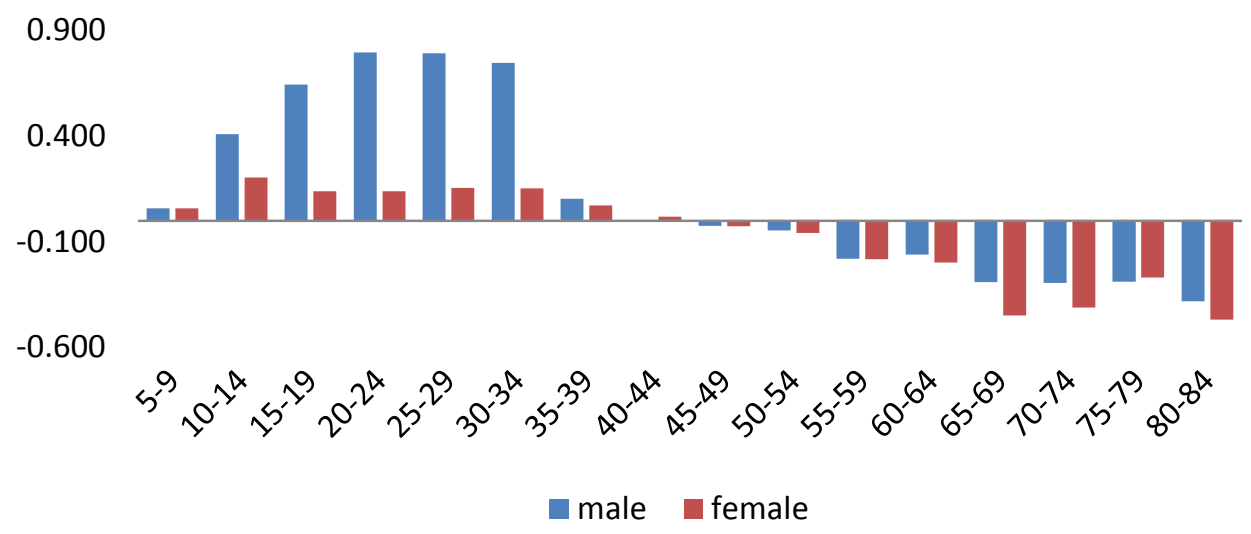


Dhillon \& Ladusingh: Working life gain from gain in old age life expectancy in India 